\title{
A prospective study of the frequency of severe pain and predictive factors in women undergoing first-trimester surgical abortion under local anaesthesia.
}

Solène Duros ${ }^{1,2,+,}$, MD, Yolaine Joueidi ${ }^{2}$, Krystel Nyangoh Timoh ${ }^{1,2}$, MD, Laurence Boyer ${ }^{2}$, MD, Paul Lemeut ${ }^{2}$, MD, Aude Tavenard ${ }^{3}$, Bruno Laviolle ${ }^{1,3}, \mathrm{MD}, \mathrm{PhD}$, Jean Levêque ${ }^{1,2}, \mathrm{MD}$, $\mathrm{PhD}$, Vincent Lavoué ${ }^{1,2,+}, \mathrm{MD}, \mathrm{PhD}$

${ }^{1}$ University of Rennes 1, Faculty of Medicine, F-35043 Rennes, France.

${ }^{2}$ CHU Rennes, Department of Gynecology and Obstetrics, F-35033 Rennes, France.

${ }^{3}$ CHU Rennes, Clinical Investigation Center, F-35033, Rennes, France.

*Corresponding author : Solène Duros, Service de gynécologie et d'obstétrique, CHU Hôpital Sud, 16 Bd de Bulgarie, BP 90347, F-35 203 Rennes Cedex 2, France.

Tel: 0033 (0)2 99265952 Fax: 0033 (0)2 992667 40. Email: solene.duros@ chu-rennes.fr

${ }^{+}$both authors contributed equally to this work.

\section{Abstract}

OBJECTIVE: To determine the frequency of severe pain among women and to identify the associated predictive factors during first-trimester surgical abortion under local anaesthesia (LA).

STUDY DESIGN: A prospective cohort study from November 2013 to January 2014 at the Department of Gynecology and Obstetrics, Rennes, France. The study population was composed of one hundred and ninety-four patients who underwent an elective first-trimester 
surgical abortion under LA. In an anonymized questionnaire, the participants were asked to self-record their perceived pain level 30 minutes after the completion of the procedure using a $10 \mathrm{~cm}$ visual analogue scale (VAS). The main outcome measure was the frequency of severe pain among women, defined as VAS $\geq 7$. Secondary outcome measure was the risk factor(s) for severe pain.

RESULTS: Severe pain (i.e. VAS $\geq 7$ ) was experienced by $46 \%$ (95\% CI: $39 \%-53 \%$ ) of the population. Multivariate analysis confirmed that > 10 weeks of gestation (OR: 2.530 [95\% CI: 1.1-5.81], $\mathrm{p}=0.0287$ ) and having 0 or 1 child (OR: 5.206 [95\% CI: 1.87-14.49], $\mathrm{p}=0.0016)$ were significant independent factors of severe pain.

CONCLUSION: Nearly half of the women experienced severe pain. More than 10 weeks of gestation and parity were predictive factors of severe pain. These findings should be useful in counselling women undergoing surgical abortion under LA.

Key word: predictive factor, surgical abortion, severe pain, local anaesthesia

\section{Introduction}

Induced abortion is one of the most common surgical procedures worldwide. In 2012, approximately 196,000 procedures were performed in England and Wales [1], 699,202 in the 
United States [2], and 225,000 in France [3]. Many first-trimester surgical procedures are performed under local anaesthesia (LA) all over the world to avoid the use of general anaesthesia or because general anaesthesia is not available. Surgical abortion below 7 weeks is rare in France, because the French Ministery of Health suggests performing abortions medically up to 7 weeks' gestational age, which can be performed without any hospitalization [4]. Despite LA, women requesting surgical abortion still experience some pain [5-10]. A survey based on almost 2,300 women seeking surgical abortion with LA showed that $78 \%$ of patients reported "moderate" or "severe" pain [11]. Even with conscious sedation (25 to $100 \mu \mathrm{g}$ fentanyl), the mean pain scores ranged from 3.4 to 4.9 out of $10 \mathrm{~cm}$ on a visual analogue scale (VAS) with dilation and from 3.8 to $7.1 \mathrm{~cm}$ with curettage $[6,12-15]$. Studies that have investigated psychological, social and medical predictive factors of pain experienced during first-trimester surgical abortion are rare $[11,16-18]$. Because LA is used in a significant number of all firsttrimester surgical abortions, it is important to identify predictive factors of severe pain in order to suggest more effective analgesia for these women, such as general anaesthesia or more efficient premedication with an oral analgesic prior to LA.

The aim of this study was to determine the frequency of severe pain among women after first-trimester surgical abortion under LA and to identify the associated predictive factors in order to seek out those patients for whom more analgesia may be necessary. 


\section{Materials and Methods}

We conducted a prospective cohort study on patients who underwent an elective firsttrimester surgical abortion under LA from November 2013 to January 2014 in the pregnancy termination clinic at Rennes Teaching Hospital, France. At this clinic, we routinely perform surgical abortions up to 14 weeks' gestational age. Surgical abortions were performed under LA (paracervical or intracervical block) or under short general anaesthesia with induction using propofol (bolus of $2 \mathrm{mcg} / \mathrm{kg}$ ) and morphomimetics (sufentanyl, remifentanyl) as desired by the patient. Eight experienced practitioners performed all procedures. All participants were informed of the study and gave their written consent to be included. The study was approved by the Institutional Review Board of the French college of obstetricians and gynecologists (Comité d'Ethique de la Recherche en Obstétrique et Gynécologie) (CEROG-2011-GYN-0803).

We recruited women seeking elective surgical abortion of an ultrasound-confirmed intrauterine pregnancy with an estimated gestational age not exceeding 98 days (14 weeks) from the first day of the preceding menstrual cycle. Participants had to be verbally fluent in French and undergoing elective surgical abortion under LA. The information concerning the difference between local or general anaesthesia was provided to the patients by the nurse and they underwent a full informed consent process as to risks, benefits, and alternatives to anaesthesia.

The termination clinic nurse approached all women seeking surgical abortion under LA after they had completed the preprocedural medical evaluation and invited them to participate in the study. Monetary incentives were not offered. Exclusion criteria included 1) surgical abortion under general anaesthesia, 2) miscarriage, 3) untreated acute cervicitis or pelvic inflammatory disease, 4) contraindications to lidocaine, 5) allergic reaction or sensitivity to midazolam or nonsteroidal anti-inflammatory drugs (NSAIDs), 6) long-term NSAID use (daily use for more 
than 3 months) , 7) history of gastritis or gastric ulcer, 8) acute renal failure or chronic renal disease, 9) chronic liver disease, 10) women who did not speak French.

All patients received oral analgesics consisting of ibuprofen $4 \times 200 \mathrm{mcg}, 7.5 \mathrm{mg}$ of oral midazolam one hour before the procedure. The choice of paracervical (PCB) or intracervical (ICB) bloc was at the physician's discretion. All women had a healthcare assistant at the bedside providing verbal and physical support (e.g., hand holding, instructions in deep breathing). As per the clinic's protocol, all women underwent cervical priming with $400 \mu \mathrm{g}$ of sublingual misoprostol two hours prior to the procedure, except women with pregnancies $\geq 12.0$ weeks' gestational age and nulliparous women with pregnancies $\geq 10$ weeks' gestational age who underwent cervical priming with $200 \mathrm{mg}$ of oral mifepristone 36 hours prior to the procedure. The surgical procedure was standard. The PCB consisted of administration of $20 \mathrm{~mL}$ of lidocaine at four and eight o'clock at the cervicovaginal reflection. The ICB was performed by injecting $20 \mathrm{~mL}$ of lidocaine at the 3, 6, 9 and 12 o'clock positions, two minutes later, cervical dilation was performed with mechanical dilators. Cervical dilation was not systematic. Vacuum aspiration was performed with an electric vacuum aspirator using a flexible Karman® cannula. The practitioners sought to use a cannula that was consistent with the participant's gestational age of pregnancy, i.e. $6 \mathrm{~mm}$ at 8 weeks' gestational age up to $12 \mathrm{~mm}$ at 14 weeks' gestational age. An ultrasound (endovaginal probe) was performed on completion to confirm that the empty uterine cavity was free of conceptus.

Sociodemographic and medical information were collected before the procedure, including age, parity, length of gestation at termination, and number of previous pregnancy terminations. In an anonymous questionnaire prior to the procedure, participants were asked to self-report the relationship of the accompanying person in the procedure room on the day of the abortion procedure, the type of first health worker approached for the abortion, the quality of the information provided by the first health worker and pregnancy termination clinic nurse 
before the surgical abortion (rated on a four-point Likert scale: 1, very satisfied, 2, relatively satisfied, 3, relatively dissatisfied, 4, very dissatisfied), the initial desired type of analgesia (local, general or undecided) before receiving information from the pregnancy termination clinic nurse, the perceived waiting time until surgical abortion (rated on a four-point Likert scale), and the level of fear before surgical abortion (rated on a $10 \mathrm{~cm}$ Visual Analogue Scale (VAS): 0-cm end indicated "no fear" and 10-cm end indicated "the worst fear ever"). In an anonymous questionnaire, the participants were asked to self-record their perceived pain level during surgical procedure, as well as to evaluate their pain alone $30 \mathrm{~min}$. after completion of the surgical procedure in order to avoid intraoperative room stress and medical team influence, using a $10 \mathrm{~cm}$ VAS: 0-cm end indicated "no pain" and 10-cm end indicated "the worst pain ever". After the surgical procedure, the practitioner reported: the type of cervical block, the degree of mechanical cervical dilation and the size of the Karman® suction cannula.

The main outcome measure was the rate of severe pain, defined as, described by Jensen et al, VAS $\geq 7$ as [19], among women during surgical abortion under LA. The secondary outcome measure was the risk factor(s) for severe pain among women seeking surgical abortion under LA.

Participants were assigned a study number. Statistical analysis was performed using SAS statistical software, version V9.4 (SAS Institute, Cary, NC, USA). The overall rate of severe pain was estimated with its associated 95\% Confidence Interval (CI) from women experiencing severe pain as a proportion of all women seeking surgical abortion under LA. The age-specific rates for severe pain were calculated and demographic and behavioural variations in rate were also investigated.

Univariate analysis was performed using a Chi2 test or Fisher's exact test as appropriate. A $P$ value of $\leq 0.05$ was considered statistically significant. Stepwise multiple logistic 
regression was performed to obtain some adjusted odds ratio (OR) for each sociodemographic factor with $\mathrm{p}<0.01$ in univariate analysis. The unadjusted ORs $(95 \% \mathrm{CI})$ associated with these risk factors were also calculated. 


\section{Results}

During the period of investigation, of the 315 women presenting at the clinic for induced abortion, 217 women underwent a surgical abortion, of which 199 under LA. Finally, 194 women who underwent a surgical abortion under LA were enrolled. The population characteristics are presented in Table 1. Mean age was 27.2 \pm 7.5 years old (range 15-45). Mean gestational age was $9.1 \pm 1.8$ weeks (range 6-14). Thirty-one percent of the enrolled women had one or more children, and $22 \%$ of them had had previous induced abortions. Thirty-two percent of the enrolled patients had already desired general anaesthesia before receiving information from the clinic nurse. The information delivered by nurses allowed changing misconceptions about general anesthesia. Seventy-one percent of them were accompanied on the day of the surgical abortion.

Mean pain during surgical abortion under LA was $5.8( \pm 2.6) \mathrm{cm}$. The rate of severe pain (i.e. VAS $\geq 7$ ) was 46\% (95\% CI: 39\%-53\%). Univariate analysis (Table 2) found that severe pain was significantly associated with age < 28 years (OR: 2.65 [95\% CI: 1.47-4.77], having 0 or 1 child (OR: 5.80 [95\% CI: 2.29-14.67]), gestation of more than 10 weeks (OR: 2.56 [95\% CI: 1.17-5.63]), having an accompanying person on the day of the surgical abortion (OR: 2.95 [95\% CI: 1.49-5.96]), PCB (OR: 1.96 [95\% CI: 1.01-3.49]), and cannula size > 8 mm (OR: 2.18 [95\% CI: 1.13-3.40]). The choice of general anaesthesia before information given by pregnancy termination clinic nurse was not a predictive factor of severe pain (OR: 1.97 [1.033.80], $\mathrm{p}=0.94)$. Multivariate analysis confirmed that $>10$ weeks of gestation (OR: 2.530 [95\% CI: $1.1-5.81], p=0.0287)$ and having 0 or 1 child (OR: 5.206 [95\% CI: $1.87-14.49], p=0.0016)$ were significant independent factors of severe pain (Table 3). 


\section{Discussion}

\section{Main Findings}

The rate of severe pain among women seeking first-trimester surgical abortion under local anesthesia was $46 \%$. The multivariable analyses identified two independent predictive and objective factors of severe pain: gestation of more than 10 weeks and having 0 or 1 child.

\section{$\underline{\text { Strengths and Limitations }}$}

Our study is the first study showing that pain decreased only from 2 children. Having one child is not correlated with less pain during surgical abortion. The lack of information on previous caesarean (because of not recorded data) is a limitation of our study. Although we analyze available data about previous cesarean and no correlation was found with severe pain (data not shown). Of note, the rate of cesarean in France is around 20\%, similar in present study. The perception of pain is highly subjective. A universal limitation of studies of pain perception is the inherent variability of the scales used to measure pain. While there are no data evaluating VAS differences during surgical abortion, the scale has already been validated for accurately measuring pain experienced during surgical procedures [20]. As previously described, confounding factors using pain scale were: anchor descriptors, methods of administration, time frames, information related to the use of scales [21]. The strength of our study is that VAS pain was evaluated by the patient alone after the surgical abortion procedure without any influence from the medical team. Singh et al. [18] analyzed pain and predictors of pain in 144 women undergoing surgical abortion, and the pain VAS was reported by the physicians and the patients, but it is well known that physicians tend to report much lower scores than the women themselves. 
This is the largest study published on pain during surgical abortion to date. The few previous studies published on this topic suggest that nulliparity [16, 22-23] and increasing gestational age are predictive factors of severe pain [11]. Other predictors of increased pain were found in univariate analyses such as a young age, retroverted uterus, history of dysmenorrhea, anxiety, expected pain and lower volume of LA used, but not in multivariate analysis [11, 16, 24-25].

One other weakness of this study is that women who wanted general anesthesia were convinced to undergo the procedure under local anesthesia. But women wanting a general anesthesia is not correlated with severe pain neither women changing their mind only after nurse information. The physician who performed surgical procedure did not inform patients. Women who still wanted to have a general anesthesia after nurse information had a general anesthesia.

Another limitation is that these findings are specific to women who received misoprostol or mifepristone at certain gestational ages. Nevertheless, according international guidelines [2627] recommend cervical priming using osmotic dilators or pharmacological agents because it may make the abortion procedure quicker and easier to perform by reducing the need for mechanical cervical dilatation. Durlot et al [28] has shown that mifepristone may facilitate cervical dilatation, making abortion under LA more comfortable and less dangerous. The baseline cervical dilatation was significantly greater among women who received mifepristone 48 hours before the operation $(\mathrm{P}=0.02)$ with no significant difference in patient acceptability compared to $800 \mu \mathrm{g}$ misoprostol vaginally 2 to 4 hours before the operation [29] suggesting lower pain with mifepristone priming cervical. Although, in our results, misoprostol is not correlated with higher pain during surgical procedure, but late first trimester termination of pregnancy is correlated with severe pain during surgical procedure, suggesting that misoprostol does not create severe pain during surgical procedure. Thus, these findings power our results that misoprostol is not a bias to generalise our results. 


\section{$\underline{\text { Interpretation }}$}

Optimization of pain control should be a priority in surgical abortion. Many studies have investigated how pain control can be improved during surgical abortion [30-31]. In a meta-analysis, Jackson et al. [31] reported the results of nine studies and found that prophylactic acetaminophen, acetaminophen+codeine, ibuprofen or alverine did not reduce abortion pain. However, administration of ibuprofen after onset of cramping reduced pain and subsequent analgesia use. Intravenous (IV) sedation is also used for pain management during surgical abortion. Allen et al. and Rawling et al. evaluated the effect of IV fentanyl with LA and demonstrated that it reduced pain scores by one point on an 11-point scale [25, 32]. Conversely, another randomized controlled trial examined the use of conscious sedation with fentanyl and PCB and showed no difference in mean pain scores [33]. The use of sublingual lorazepam was associated with more dissatisfaction and no reduction in pain [25]. Some studies evaluated the efficacy of nitrous oxide (NO) with PCB for pain management in surgical abortion. Pain scores were similar between patients treated with NO versus intravenous sedation [34-35] and overall adverse effects were significantly higher in the NO group [34]. Use of hypnosis has also been investigated and women who underwent hypnosis required less intravenous sedation analgesia and NO [36]. PCB is a predictor of severe pain in univariate analysis, leading us to prefer ICB. Mankowsky et al. recommended using an ICB because it is an easier technique to teach [15].

Thus, apart from ibuprofen (used in our study), additive treatment with LA did not significantly reduce pain during surgical abortion with LA.

\section{Conclusion}


We pointed out two obvious predictive factors ( 0 or 1 child and $>10$ weeks of gestation) that independently correlated with severe pain and that proved to be useful in clinical practice. However, they are not the sole determining factors for who receives local versus general anaesthesia. The type of anaesthesia must be chosen depending on the decision taken with patient in view of level pain tolerance. Furthermore, higher power studies are required to show more criteria correlating with severe pain and determine scores to strictly screen patients to be referred to general anaesthesia. 


\section{References}

[1] Department of Health: Abortion statistics, England and Wales. 2010,. Statistical Bulletin 2010/05. Crown 2011.

[2] Pazol K, Creanga AA, Jamieson DJ. Abortion Surveillance - United States, 2012. MMWR Surveill Summ 2015;64: 1-40.

[3] Vilain A. MM-C. Les interruptions volontaires de grossesse en 2013. Études et Résultats, DREES 2015; bulletin $\mathrm{n}^{\circ} 884$..

[4] Haute Autorité de Santé. Recommandations de bonne pratique clinique: Interruption volontaire de grossesse par méthode médicamenteuse. 2010.

[5] Wiebe ER. Comparison of the efficacy of different local anesthetics and techniques of local anesthesia in therapeutic abortions. Am J Obstet Gynecol 1992;167: 131-4.

[6] Miller L, Jensen MP, Stenchever MA. A double-blind randomized comparison of lidocaine and saline for cervical anesthesia. Obstet Gynecol 1996;87: 600-4.

[7] Glantz JC, Shomento S. Comparison of paracervical block techniques during first trimester pregnancy termination. Int J Gynaecol Obstet 2001;72: 171-8.

[8] Lowenstein L, Granot M, Tamir A, Glik A, Deutsch M, Jakobi P, Zimmer EZ. Efficacy of suppository analgesia in postabortion pain reduction. Contraception 2006;74: 345-

[9] Agostini A, Provansal M, Collette E, Capelle M, Estrade JP, Cravello L, Gamerre M. Comparison of ropivacaine and lidocaine for paracervical block during surgical abortion. Contraception 2008;77: 382-5.

[10] Tangsiriwatthana T, Sangkomkamhang US, Lumbiganon P, Laopaiboon M. Paracervical local anaesthesia for cervical dilatation and uterine intervention. Cochrane Database Syst Rev 2009: CD005056.

[11] Smith GM, Stubblefield PG, Chirchirillo L, McCarthy MJ. Pain of first-trimester abortion: its quantification and relations with other variables. Am J Obstet Gynecol 1979;133: 489-98.

[12] Kan AS, Ng EH, Ho PC. The role and comparison of two techniques of paracervical block for pain relief during suction evacuation for first-trimester pregnancy termination. Contraception 2004;70: 159-63.

[13] Wiebe ER, Trouton KJ, Savoy E. Intra-cervical versus i.v. fentanyl for abortion. Hum Reprod 2005;20: 2025-8.

[14] Phair N, Jensen JT, Nichols MD. Paracervical block and elective abortion: the effect on pain of waiting between injection and procedure. Am J Obstet Gynecol 2002;186: 1304-7. 

lidocaine for suction curettage: a randomized controlled trial. Obstet Gynecol 2009;113: 1052-7.

[16] Belanger E, Melzack R, Lauzon P. Pain of first-trimester abortion: a study of psychosocial and medical predictors. Pain 1989;36: 339-50.

[17] Borgatta L, Nickinovich D. Pain during early abortion. J Reprod Med 1997;42: 287-93.

[18] Singh RH, Ghanem KG, Burke AE, Nichols MD, Rogers K, Blumenthal PD. Predictors and perception of pain in women undergoing first trimester surgical abortion. Contraception 2008;78: 155-61.

[19] Jensen MP, Miller L, Fisher LD. Assessment of pain during medical procedures: a comparison of three scales. Clin J Pain 1998;14: 343-9.

[20] Todd KH, Funk KG, Funk JP, Bonacci R. Clinical significance of reported changes in pain severity. Ann Emerg Med 1996;27: 485-9.

[21] Hjermstad MJ, Fayers PM, Haugen DF, Caraceni A, Hanks GW, Loge JH, Fainsinger R, Aass N, Kaasa S. Studies comparing Numerical Rating Scales, Verbal Rating Scales, and Visual Analogue Scales for assessment of pain intensity in adults: a systematic literature review. J Pain Symptom Manage 2011;41: 1073-93.

[22] Penney G. Treatment of pain during medical abortion. Contraception 2006;74: 45-7.

[23] Suhonen S, Tikka M, Kivinen S, Kauppila T. Pain during medical abortion: predicting factors from gynecologic history and medical staff evaluation of severity. Contraception 2011;83: 357-61.

[24] Allen RH, Fortin J, Bartz D, Goldberg AB, Clark MA. Women's preferences for pain control during firsttrimester surgical abortion: a qualitative study. Contraception 2012;85: 413-8.

[25] Allen RH, Kumar D, Fitzmaurice G, Lifford KL, Goldberg AB. Pain management of first-trimester surgical abortion: effects of selection of local anesthesia with and without lorazepam or intravenous sedation. Contraception 2006;74: 407-13.

[26] The Royal College of Obstetricians and Gynaecologists. The Care of Women Requesting Induced Abortion. Evidence-based Clinical Guideline Number 72011.

[27] Society of Obstetricians and Gynaecologists of Canada. Induced Abortion Guidelines. No 184, November 2006

[28] Durlot F, Dubois C, Brunerie J, Frydman R. Efficacy of progesterone antagonist RU486 (mifepristone) for pre-operative cervical dilatation during first trimester abortion. Hum Reprod 1988;3: 583-4. 
[29] Ashok PW, Flett GM, Templeton A. Mifepristone versus vaginally administered misoprostol for cervical priming before first-trimester termination of pregnancy: a randomized, controlled study. Am J Obstet Gynecol 2000;183: 998-1002.

[30] Renner RM, Jensen JT, Nichols MD, Edelman AB. Pain control in first-trimester surgical abortion: a systematic review of randomized controlled trials. Contraception 2010;81: 372-88.

[31] Jackson E, Kapp N. Pain control in first-trimester and second-trimester medical termination of pregnancy: a systematic review. Contraception 2011;83: 116-26.

[32] Rawling MJ, Wiebe ER. A randomized controlled trial of fentanyl for abortion pain. Am J Obstet Gynecol 2001;185: 103-7.

[33] Wong CY, Ng EH, Ngai SW, Ho PC. A randomized, double blind, placebo-controlled study to investigate the use of conscious sedation in conjunction with paracervical block for reducing pain in termination of first trimester pregnancy by suction evacuation. Hum Reprod 2002;17: 1222-5.

[34] Kan AS, Caves N, Wong SY, Ng EH, Ho PC. A double-blind, randomized controlled trial on the use of a 50:50 mixture of nitrous oxide/oxygen in pain relief during suction evacuation for the first trimester pregnancy termination. Hum Reprod 2006;21: 2606-11.

[35] Singh RH, Montoya M, Espey E, Leeman L. Nitrous oxide versus oral sedation for pain management of first trimester surgical abortion - a randomized study Contraception. 2017 Aug ; 96 (2) :118-123.

[36] Marc I, Rainville P, Verreault R, Vaillancourt L, Masse B, Dodin S. The use of hypnosis to improve pain management during voluntary interruption of pregnancy: an open randomized preliminary study. Contraception 2007;75: 52-8. 
Figure 1: Flowchart of participants during the study period.

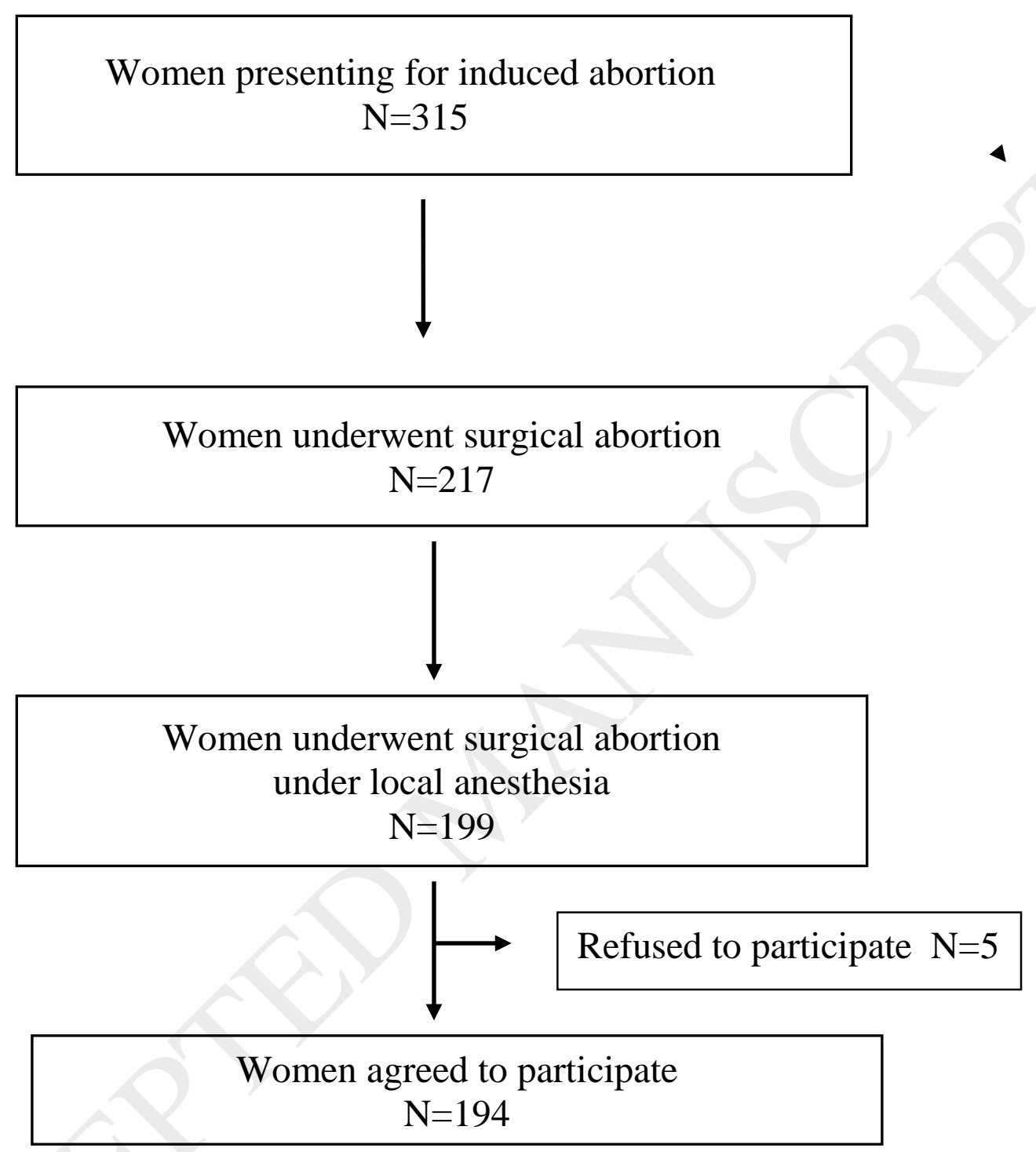


Table 1. Characteristics of women seeking surgically induced abortion. 
*Total numbers may not equal 194 due to missing data.

\section{Variables}

(

Age in years

Body Mass Index

No. children (live births)

0

1

2

3 or more

No. miscarriages

0

1 or more
$133(68.6)$

$24(12.4)$

$22(11.3)$

$15(7.7)$

$158(81.4)$

$36(18.6)$

No. previous abortions

$$
\begin{aligned}
& 0 \\
& 1 \\
& 2 \text { or more }
\end{aligned}
$$

$148(76.3)$

$31(16.0)$

$12(6.2)$

Weeks of gestation for surgical abortion

$9.1( \pm 1.8)$

6-8

$74(43.3)$

9-10

$64(37.4)$

$22(12.8)$

11-12

$11(6.4)$

13-14

$98(51.3)$

$15(16.5)$

$78(40.8)$

Desired type of analgesia before information given by pregnancy termination clinic nurse

Local anesthesia

General anesthesia

Undecided

Accompanying person on the day of surgical abortion

Alone

Partner

$68(35.2)$

Friend

$39(20.2)$

Family member 
Table 2. Characteristics associated with severe pain (VAS $\geq 7$ ) among women seeking surgically induced abortion under local anesthesia

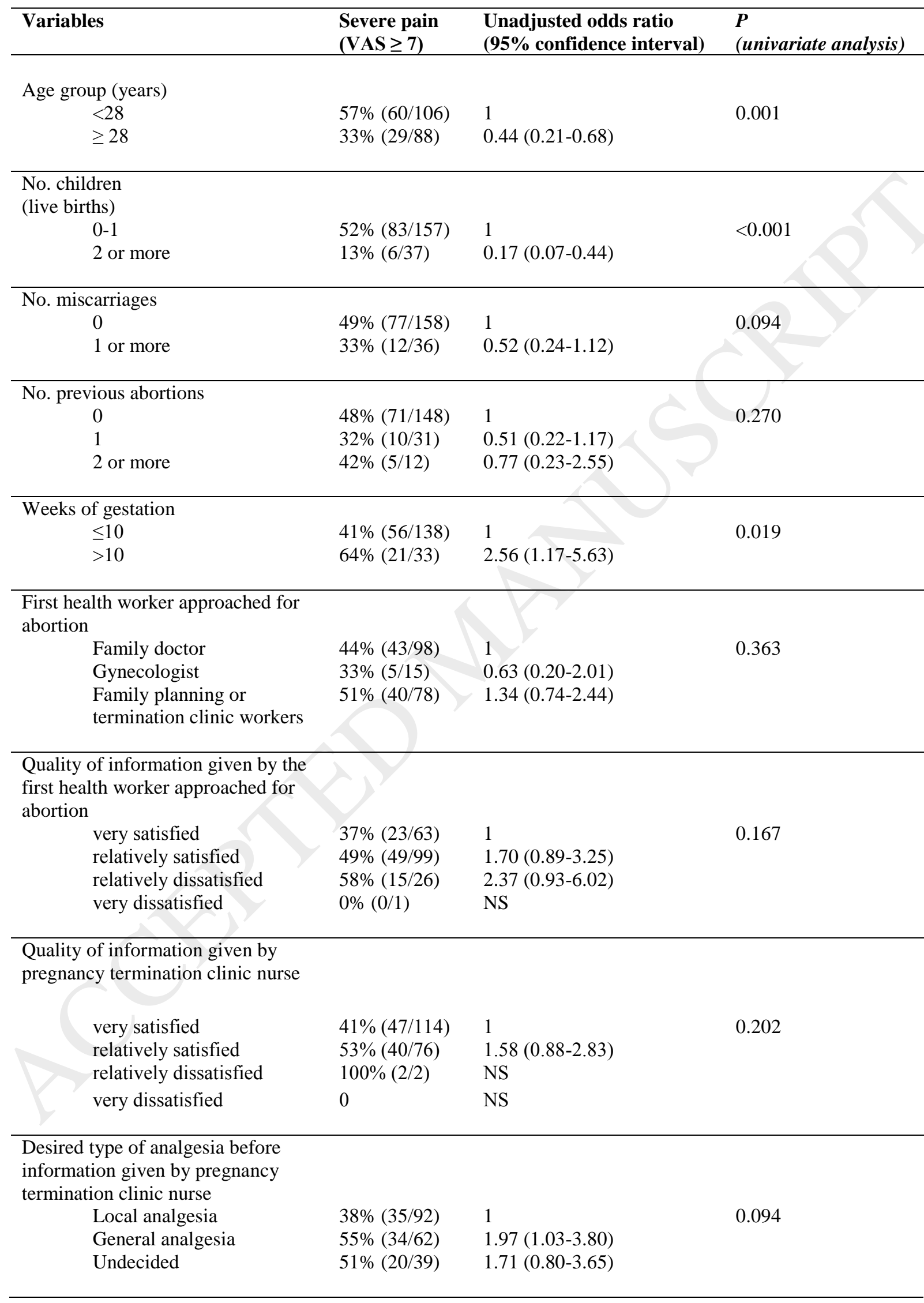




\begin{tabular}{|c|c|c|c|}
\hline $\begin{array}{l}\text { Perceived waiting time by women } \\
\text { until surgical abortion } \\
\text { very satisfied } \\
\text { relatively satisfied } \\
\text { relatively dissatisfied } \\
\text { very dissatisfied }\end{array}$ & $\begin{array}{l}38 \%(15 / 39) \\
41 \%(28 / 69) \\
51 \%(34 / 67) \\
69 \%(11 / 16)\end{array}$ & $\begin{array}{l}1 \\
1.09(0.49-2.44) \\
1.64(0.74-3.70) \\
3.52(1.02-12.15)\end{array}$ & 0.130 \\
\hline $\begin{array}{l}\text { Level of fear before surgical } \\
\text { abortion } \\
\qquad \begin{array}{l}\text { Mild }(<4) \\
\text { Moderate }(\geq 4 \text { to }<7) \\
\text { Severe }(\geq 7 \text { to } \leq 10)\end{array}\end{array}$ & $\begin{array}{l}47 \%(14 / 30) \\
38 \%(26 / 68) \\
51 \%(44 / 87)\end{array}$ & $\begin{array}{l}1 \\
0.71(0.38-2.24) \\
1.16(0.51-2.69)\end{array}$ & 0.308 \\
\hline $\begin{array}{l}\text { Accompanying person on the day of } \\
\text { surgical abortion } \\
\text { Alone } \\
\text { Partner } \\
\text { Friend } \\
\text { Family member }\end{array}$ & $\begin{array}{l}30 \%(17 / 56) \\
53 \%(36 / 68) \\
51 \%(20 / 39) \\
53 \%(15 / 30)\end{array}$ & $\begin{array}{l}1 \\
2.58(1.23-5.42) \\
2.41(1.03-5.64) \\
2.29(1.05-6.55)\end{array}$ & 0.047 \\
\hline $\begin{array}{r}\text { Analgesia } \\
\text { Paracervical } \\
\text { Intracervical }\end{array}$ & $\begin{array}{l}53 \%(57 / 107) \\
37 \%(32 / 87)\end{array}$ & $\begin{array}{l}1 \\
0.51(0.28-0.91)\end{array}$ & 0.021 \\
\hline $\begin{array}{l}\text { Preoperative cervical dilation } \\
\text { No } \\
\text { Yes }\end{array}$ & $\begin{array}{l}41 \%(49 / 119) \\
55 \%(28 / 51)\end{array}$ & $\begin{array}{l}1 \\
1.73(0.89-3.37)\end{array}$ & 0.099 \\
\hline $\begin{array}{l}\text { If cervical dilation used, degree of } \\
\text { cervical dilation } \\
\qquad \begin{array}{l}\leq 8 \mathrm{~mm} \\
\quad>8 \leq 10 \mathrm{~mm} \\
>10 \mathrm{~mm}\end{array}\end{array}$ & $\begin{array}{l}35 \%(8 / 23) \\
69 \%(11 / 16) \\
34 \%(7 / 11)\end{array}$ & $\begin{array}{l}1 \\
4.12(1.06-16.10) \\
3.28(0.73-14.69)\end{array}$ & 0.077 \\
\hline $\begin{array}{l}\text { Size of suction cannula } \\
\qquad \begin{array}{l}\leq 8 \mathrm{~mm} \\
>8 \leq 10 \mathrm{~mm} \\
>10 \mathrm{~mm}\end{array}\end{array}$ & $\begin{array}{l}42 \%(56 / 134) \\
58 \%(14 / 24) \\
37 \%(7 / 11)\end{array}$ & $\begin{array}{l}1 \\
1.95(0.81-4.70) \\
2.43(0.68-8.73)\end{array}$ & 0.149 \\
\hline
\end{tabular}

NS: not stated 
Table 3. Multivariate logistic regression model

\begin{tabular}{lccc}
\hline Variables & Adjusted OR & $\begin{array}{c}\text { 95\% Confidence } \\
\text { Interval }\end{array}$ & $\boldsymbol{P}$ \\
\hline Having 0 or 1 child & 5.206 & {$[1.87 ; 14.49]$} & 0.002 \\
$>10$ weeks of gestation & 2.530 & {$[1.1 ; 5.81]$} & 0.029 \\
\hline Variables included: years $\geq 28$, having 0 or 1 child, number of miscarriages $\geq 1$, weeks of gestation > \\
10, desired type of analgesia, accompanying person on the day of surgical abortion, analgesia, \\
preoperative cervical dilation
\end{tabular}

